\title{
FEMINICÍDIO NÃO \\ A CAMPANHA DO GOVERNO DO ESTADO DE SÃO PAULO NO CRESCIMENTO DAS ESTATÍSTICAS*
}

\author{
Kátia Aparecida Bizan França
}

RESUMO

Uma pesquisa do Fórum Brasileiro de Segurança Pública, apresentada em fevereiro/19, revela que só $10 \%$ das mulheres que se tornam vítimas de algum tipo de agressão registram ocorrência em uma delegacia e, segundo a SSP-SP, o número de feminicídios aumentou 76\% no primeiro trimestre de 2019. Com esses números em mãos, o governo do estado de São Paulo desenvolveu uma campanha para incentivar tanto as vítimas, quanto pessoas próximas a denunciar casos de agressões, além de informar que foram disponibilizadas novas delegacias 24 horas exclusivamente para atendimento das mulheres e, também, o aplicativo SOS Mulher que aciona por GPS o atendimento policial mais próximo. Aplicaremos da análise semiótica para o estudo desta campanha em conjunto com pesquisas bibliográficas, utilizando como principais referências: A Dominação Masculina - Pierre Bourdieu; Violência Contra Mulheres - A Vulnerabilidade Feminina e o Perfil dos Agressores - Adriana Bigliardi; Semiótica-Charles Peirce, entre outros. A justificativa deste artigo vem em encontro com minha tese sobre o feminicídio e a influência do patriarquismo, em que é preciso se investigar porque a mulher ainda é vítima de uma violência que está distante de ser acolhida em sua extensão e profundidade.

Palavras-chave: feminicídio não; campanha; governo de São Paulo; comunicação; violência.

\section{ABSTRACT}

A survey by the Brazilian Public Security Forum, presented in February, reveals that only $10 \%$ of women who become victims of some type of aggression report their occurrence in a police station and, according to the São Paulo Public Security Secretariat, the number of femicides increased $76 \%$ in the first quarter of 2019. With these numbers in hand, the São Paulo state government has developed a campaign to encourage both victims and those

* Trabalho apresentado GT 1 - Comunicação, Cultura e Sociabilidade, Cidadania do MEDIACOM 2019. 
close to them to report cases of aggression, and to report that new police stations have been made available 24 hours a day. exclusively for the care of women and also the SOS Woman app that triggers the nearest police service by GPS. We will apply semiotic analysis to the study of this campaign in conjunction with bibliographic research, using as main references: The Male Domination - Pierre Bourdieu; Violence Against Women - Female Vulnerability and the Profile of Offenders - Adriana Bigliardi; Semiotics-Charles Peirce, among others. The justification for this article is in line with my thesis on femicide and the influence of patriarchy, which needs to be investigated because women are still victims of violence that is far from being welcomed in its extent and depth.

Keywords: no femicide; campaign; São Paulo government; communication; violence.

\section{VIOLENNCIA EM SP}

Segundo estudos realizados pela SSP-SP (Secretaria de Segurança Pública do Estado de São Paulo) o número de feminicídios, contabilizados entre janeiro e maio de 2016 a 2019 aumentaram 267\% e uma pesquisa do Fórum Brasileiro de Segurança Pública indica que só $10 \%$ das vítimas brasileiras registram boletim de ocorrência em caso de agressão.

A SSP-SP revelou, também, que entre janeiro em novembro de 2018 houve 121 feminicídios no estado e 8.814 registros de agressões, sendo mais de 26 casos por dia.

Conforme o levantamento "Raio-X do Feminicídio em SP - é possível evitar a morte" com dados referentes ao ano de 2018 produzido pelo Núcleo de Gênero do Ministério Público do Estado de São Paulo, foi possível verificar informações mais específicas deste tipo de crime, como:

- Dias dos crimes:

- $68 \%$ de segunda a sexta-feira;

- $17 \%$ domingo;

- $15 \%$ aos sábados.

- Horário dos crimes:

- $\quad 35 \%$ entre $18 \mathrm{~h}$ e $24 \mathrm{~h}$;

- $21 \%$ entre $24 \mathrm{~h}$ e $6 \mathrm{~h}$;

- $20 \%$ entre $6 \mathrm{~h}$ e $12 \mathrm{~h}$;

- $19 \%$ entre $12 \mathrm{~h}$ e $18 \mathrm{~h}$;

- $5 \%$ não informado;

Disponível em http://www.mpsp.mp.br/portal/page/portal/Nucleo_de_Genero/Feminicidio/2018\%20-

-\%20RAIOX\%20do\%20FEMINICIDIO\%20pdf.pdf - Acesso em 06 ago. 2019 
- Locais do crime:

- $66 \%$ na casa das vítimas;

- $6 \%$ em via pública;

- $5 \%$ em estabelecimento público ou trabalho;

- $3 \%$ em casas de terceiros / casa do réu ou trajeto da vítima;

- $2 \%$ no carro ou local ermo.

- A cada três tentativas de feminicídio, uma aconteceu;

- Instrumento do crime:

- Em 58\% dos feminicídios a arma utilizada foi faca, foice ou canivete;

- $17 \%$ uso de arma de fogo;

- $11 \%$ uso de instrumentos "domésticos";

- $10 \%$ uso das mãos e $4 \%$ outros.

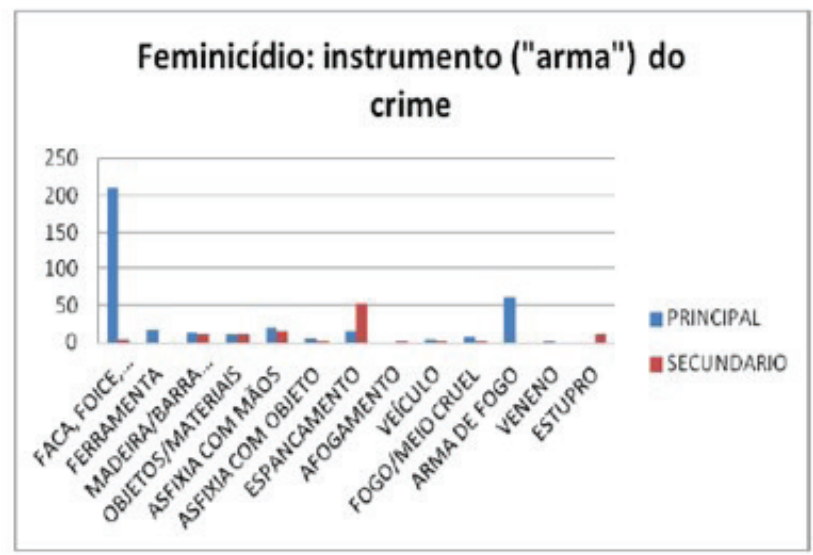

Neste gráfico constam o os seguintes dados: faca ( foice, canivete, arma branca); ferramenta (chave de fenda, martelo, chave de rodas etc); madeira ou barra de ferro; objetos (da casa como panela de pressão, cabo, móveis etc) e materiais de construçăo (tijolo e similares); asfixia com as mãos; asfixia com objeto (como cabo de telefone celular, fio do ferro elétrico, saco plástico e outros); afogamento; veiculo (carro usado para atropelar a vítima); fogo ou meio cruel ( fogo na vitima, na casa, jogar ácido no rosto), arma de fogo (revólver, espingarda e similares), veneno (como veneno de rato e similares) e estupro (cometido antes do feminicidio ou após a conduta mais grave).

Figura 1: Meios mais usados para o feminicídio em SP - $2018^{2}$

\footnotetext{
2 Disponível em http://www.mpsp.mp.br/portal/page/portal/Nucleo_de_Genero/Feminicidio/2018\%20-\%20RAIOX\%20do\%20FEMINICIDIO\%20pdf.pdf - Acesso em 10 ago. 2019
} 
- Intensidade dos ataques

- Em 48\% deles foram com diversos golpes e/ou tiros;

- $18 \%$ com um golpe ou um tiro;

- $10 \%$ por asfixia ou meio cruel;

- $8 \%$ se igualaram os por meios por espancamento / tentativa "branca" e um golpe ou um tiro.

- Nos casos de relação afetiva direta entre a vítima e o assassino, em:

- $70 \%$ deles o assassino era convivente (ou ex) da vítima;

- $14 \%$ das vezes era o cônjuge (ou ex);

- $12 \%$ era o namorado (ou ex);

- $2 \%$ tinha um relacionamento com a profissional do sexo;

- $1 \%$ se iguala em ter um relacionamento extraconjugal com a vítima ou afeto não correspondido.

- Quando não é uma relação afetiva direta, as vítimas de feminicídios foram em:

- $18 \%$ dos casos a mãe do réu;

- $14 \%$ desconhecidas do assassino;

- $13 \%$ eram amigas;

- $11 \%$ irmã;

- $10 \%$ vizinha;

- $8 \%$ cunhada;

- $7 \%$ sogra;

- $5 \%$ nora;

- $3 \%$ tia ou filha;

- $1 \%$ enteada ou sobrinha.

- Motivo do crime em relação afetiva direta:

- $45 \%$ dos casos foi a separação recente do casal ou pedido de rompimento;

- $30 \%$ ciúmes, sentimento de posse ou machismo;

- $\quad 17 \%$ por discussão;

- $6 \%$ não consta motivo;

- $2 \%$ motivo financeiro 
Além da vítima do feminicídio, o levantamento verificou também que em 26\% dos casos houve vítimas diretas (filhos, mãe, novo companheiro, parentes, vizinhos, amigos etc. que estavam presentes ou sofreram ataques / violência durante o momento do crime) e vítimas indiretas (que sofreram algum tipo de sofrimento psicológico com a perda da vítima).

\section{PROTEÇÃO BRASILEIRA}

No Brasil contamos com leis para combater o feminicídio como:

- Lei Maria da Penha (Lei 11.340)33;

Foi indicada entre as três melhores legislações do mundo para o combate à violência contra a mulher. Esta lei foi sancionada pelo ex-presidente Luiz Inácio Lula da Silva, sendo incluso o parágrafo 9 em seu Artigo 129 do Código Penal Brasileiro, que entrou em vigor em setembro de 2006.

- Lei do Feminicídio (Lei 13.104);

Sancionada em 2015 pela ex-presidente Dilma Rousseff, modificou o código penal (art.121 do Decreto Lei $\mathrm{n}^{\circ} 2.848 / 40$ ), em que o feminicídio se torna um homicídio qualificado constando no rol de crimes hediondos, isto é, são considerados de suprema gravidade e recebem um tratamento distinto / rígido que abrange o acréscimo em $1 / 3$ (um terço) da pena se acontecer durante a gestação ou até três meses depois; pessoa menor de 14 anos ou maior de 60 anos; na presença de descendentes ou ascendentes da vítima;

Além da:

- Lei da importunação sexual (Lei 13.718);

- Sancionada pelo Ministro do STF José Antonio Dias Toffoli em 2018, a qual aumenta a pena para o estupro coletivo e torna crime a importunação sexual e divulgação de cenas de estupro.

- $\quad$ Lei do Estupro (Lei 12.015) ${ }^{6}$

Sancionada pelo ex-presidente Luiz Inácio Lula da Silva em 2009, esta lei trouxe importantes alterações no Código Penal Brasileiro,

3 Disponível em http://www.planalto.gov.br/ccivil_03/_ato2004-2006/2006/lei/111340.htm - Acesso em 26 ago. 2019

4 Disponível em http://www.planalto.gov.br/ccivil_03/_ato2015-2018/2015/lei/113104.htm - Acesso em 26 ago. 2019

5 Disponível em https://www12.senado.leg.br/noticias/materias/2018/09/25/sancionada-lei-que-aumenta-pena-para-estupro-coletivo-e-tipifica-a-importunacao-sexual - Acesso em 26 ago. 2019

6 Disponível em http://www.planalto.gov.br/ccivil_03/_Ato2007-2010/2009/Lei/L12015.htm - Acesso em 26 ago. 2019 
onde uniu os crimes de atentado violento ao pudor ao crime de estupro; supriu o conceito de presunção de violência por estupro de vulnerável; alterou a redação do crime de corrupção de menores para atos sexuais com menores fixando a idade de consentimento no Brasil em 14 anos e tornou os crimes sexuais contra menores uma ação pública incondicionada, ou seja, cabe ao Ministério Público processar estes casos independente da vontade da família da vítima.

Apesar disso ainda é baixo o número de mulheres que realizam o boletim de ocorrência e / ou solicitam medidas protetivas como uma possível prevenção ao feminicídio.

Conforme o mesmo levantamento do Núcleo de Gênero do MP-SP, foi verificado que, em vias de regra, os feminicídios acontecem menos se a mulher tem uma medida protetiva. No total de 364 casos, somente 3\% deles tinham medida protetiva.

No que se refere a realização de boletim de ocorrência, somente 4\% (5 casos) já tinham feito algum registro oficial contra o agressor. Nos outros casos não houve nenhum tipo de registro criminal para auxílio da justiça antes do assassinato, sendo:

- Caso 1 - registro de BO de ameaça 3 dias antes da morte;

- Caso 2 - registro de dois BOs, um por ameaça e um por lesão, respectivamente 21 e 15 dias antes da morte;

- Caso 3 - registro de BO por lesão dois anos antes da morte;

- Caso 4- registro de 3 BOs e deferimento de medidas protetivas, no período de seis meses a um mês antes do fato, inclusive por desobediência;

- Caso 5 - registro de um BO por lesão, 06 meses antes da morte.

O levantamento permitiu verificar que:

- Não há dia nem hora para a prática do crime;

- Não precisa estar sob efeito de álcool para realizar o assassinato;

- O assassino, em regra, é do convívio da vítima;

- Os principais motivos indicados foram por separação ou pedido de rompimento não aceito pelo agressor e ciúmes ou posse;

- O assassino utiliza mais de instrumentos "caseiros" que se mostraram ao alcance durante o ataque e com repetição de golpes;

- Além das vítimas, o feminicídio atinge outras vítimas diretamente e indiretamente. 


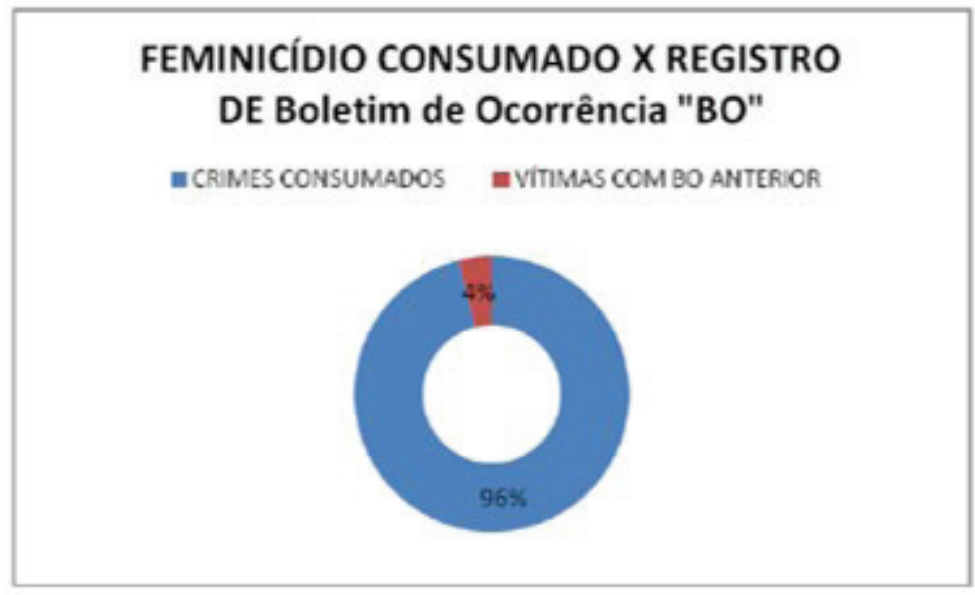

Figura 2: Feminicídios com e sem Boletim de Ocorrência1

A partir desses dados podemos dizer que o feminicídio é praticado, muitas vezes, como "resolução final" para situações em que o agressor não quer que seja resolvido de outra forma fora de sua vontade em seu imaginário individual.

Com esse imaginário de superioridade do homem em ação, a submissão da mulher se torna automática em seu subconsciente, em que a subordinação a sua vontade é superior e deve ser respeitada, pois, caso não a seja, o uso da violência é usado como recurso para se conseguir este respeito / obediência ou, então, de meios extremos, como o feminicídio.

Bourdieu (2007, p. 27) nos diz que

o princípio da inferioridade e da exclusão da mulher, que o sistema mítico-ritual ratifica e amplia, a ponto de fazer dele o princípio de divisão de todo o universo, não é mais que a dissimetria fundamental, a do sujeito e do objeto, do agente e do instrumento, instaurada entre o homem e a mulher no terreno das trocas simbólicas, das relações de produção e reprodução do capital simbólico.

Este capital simbólico, que chamamos de prestígio, carrega o imaginário cultural coletivo de muitas épocas com a manifestação do masculino, e sua masculinidade, a frente de qualquer situação de decisão, como a familiar e a profissional, em que a decisão final é registrada como devendo ser do homem.

Disponível em http://www.mpsp.mp.br/portal/page/portal/Nucleo_de_Genero/Feminicidio/2018\%20-

-\%20RAIOX\%20do\%20FEMINICIDIO\%20pdf.pdf - Acesso em 10 ago. 2019 
Dentro do imaginário coletivo o arquétipo do "homem macho / guerreiro" foi construído através dos anos e das culturas recebendo intensos reforços da publicidade e cobranças sociais e, assim, o imaginário legitima essa identidade e seus objetivos propostos pela sociedade para apropriação de um poder simbólico imposto para legitimar suas ações.

A comunicação ao imaginário é uma articulação simbólica que traz sentido com a imagem produzida e se traz sentido é o que importa num momento de decisão.

Monick (1993, p. 10) nos diz que

masculinidade arquetípica significa concentrar-se sobre o falo, o pênis ereto, o emblema e padrão da masculinidade. Todas as imagens através das quais a masculinidade é definida tem o falo como ponto de referência. Fortaleza, determinação, eficácia, penetração, avanço, dureza, força, tudo isso é efetivado pelo falo que é a autoridade subjetiva para um homem, e objetiva para aqueles que entram em contato com ele se apresentando como um deus o faria.

Monick (idem, p.9) diz, também, que "para muitos homens, a dominação masculina é tomada como certa, tão familiar é sua experiência de possuir status superior", momento aqui de ponto sobre a reflexão da profunda influência do patriarcado no imaginário cultural / social quanto a submissão feminina.

O patriarcado, ou patriarcalismo, vem do acordo entre as expressões gregas pater (pai) e arkhe (origem e comando), que tem como forma de organização social a centralidade de poder ao homem, em que predomina sua autoridade ou dominação masculina que deriva em opressão das mulheres por meio da ideologia masculina.

A influência da ideologia masculina recebeu legitimação das posturas religiosas para assegurar o patriarcado durante a história humana, em que o homem é colocado como o representante forte e legítimo da espécie, o qual precisa defender - sem desvios - sua posição / orientação sexual para procriação e perpetuar a espécie.

A ideologia masculina, ou as ideologias masculinas, se manifestam enquanto fenômeno nas mais diversas culturas, seja atualmente ou em distintos períodos históricos. Entender que a ideologia, enquanto "consciência social prática", possui origens anteriores ao surgimento das classes sociais e do patriarcado, é também uma forma de se prevenir de possíveis atribuições feitas à dominação masculina apenas a partir do patriarcado ou do advento 
da propriedade privada. Tais linhas de pensamentos ofuscam o problema da subjetividade por delimitar a dominação de um gênero sobre outro a apenas momentos específicos. (BRITO e PAULA, 2013, p. 185)

Observamos, assim, que a opressão contra as mulheres vem sendo acompanhada das mudanças sociais durante a evolução humana, as quais podem ter gerado uma crise de identidade masculina, momento em que o homem pode se sentir perdendo o significado sobre a masculinidade conhecida por ele e, assim, busca o uso da violência para tentar obter este status de patriarca de volta podendo chegar ao feminicídio para demonstrar sua superioridade. Russel e Caputti (1992, p. 2) nos dizem que

femicídio está no ponto mais extremo de um continuum de terror antifeminino que inclui uma vasta gama de abusos verbais e físicos, tais como estupro, tortura, escravidão sexual, abuso sexual infantil incestuoso e extrafamiliar, espancamento físico e emocional, assédio sexual, mutilação genital, operações ginecológicas desnecessárias, heterossexualidade forçada, esterilização forçada, maternidade forçada (ao criminalizar a contracepção e o aborto), psicocirurgia, privação de comida para mulheres em algumas culturas, cirurgias cosméticas e outras mutilações em nome do embelezamento. Onde quer que estas formas de terrorismo resultem em mortes, elas se tornam feminicídios.

Em toda a história o homem sempre prevaleceu como sendo eminente. Desde a bíblia cristã, em que Deus é representado em forma de homem para ser reconhecido e respeitado pelos humanos até as histórias infantis contadas ou assistidas, inclusive nos dias atuais, em que o príncipe é quem salva a princesa. Este processo induziu (induz) o imaginário social coletivo que tornou a ideologia da masculinidade uma forma de práxis social, a qual "justifica" a conduta privilegiada do homem concedendo, então, este poder imaginário de magnânimo.

Finco (2019, p. 2), nos diz que este tipo de superioridade por gênero pode ser percebido desde a pré-escola

A justificativa inicial para essa prática pedagógica (organização das "filas de meninas" e das "filas de meninos") é a necessidade de organização para a locomoção espacial. Porém, [...] foi possível perceber que a justificativa para essa prática pedagógica também está relacionada à uma prática disciplinar baseada na ideia de que as meninas são mais frágeis, organizadas e obedientes. 
Percebemos, assim, que desde muito cedo é imposto a mulher a obediência para com a pessoa representada no comando, seja o seu pai, avô, tio, professor, padre / pastor e, posteriormente, ao marido, em que sempre é exigido ao seu papel de mulher servir e obedecer.

Brito e Paula (2013, p. 178) nos explicam que

A mulher se torna mero apêndice da família no processo, assumindo um papel secundário, passivo. Para o homem, ser o chefe de família representa muito mais que ser o provedor financeiro do lar, cabe a ele, também, a responsabilidade de vigiar os comportamentos que não correspondam à disciplina e moral cristã. $\mathrm{O}$ que resulta na vigilância constante da sexualidade dos filhos. Assuntos como virgindade, namoro etc., são de suma importância para o homem e é dele a responsabilidade de monitorar, portanto, as relações sociais que seus filhos e esposa mantêm, impedindo que questões como sexualidade, homossexualidade, aborto etc., sejam sequer tocadas, pois tais questões vão contra o dogma cristão.

Bigliardi e Antunes (2018) nos esclarecem que a violência contra a mulher se funde a cultura e estes são transmitidos de geração em geração. A família é o mais importante instrumento de continuidade da violência que, normalmente, começa na infância, em que a criança sofre ou presencia cenas de violência e acaba por reproduzir o que sofreu ou sentiu para seus futuros envolvimentos íntimos, prejudicando sua capacidade de criar e/ou manter relacionamentos.

Podemos entender que a violência é uma grande "bola de neve", a qual pode começar com (nada) simples empurrão e/ou xingamentos entre o casal e ser aceito como "coisas normais de casal". A partir deste aceite do "normal", tal movimento vai tomando proporções maiores até se tornarem brigas físicas por ciúmes, financeiros, etc. que afetarão ou envolverão seus filhos e estes carregarão em seu psicológico as experiências vividas que serão transmitidas para seus descendentes e assim por diante.

O aspecto mais perturbador é que o feminicídio vem, normalmente, como uma consequência extrema da violência de crianças que sofreram algum tipo de abuso psicológico ou sexual e, assim, carregam a insegurança $/$ medo de perder. 


\section{CAMPANHA PUBLICITÁRIA}

Em 2018, com a publicação do levantamento sobre feminicídio no estado pelo MP-SP, foi lançada a campanha do governo do estado de São Paulo denominada "Feminicídio não". Com o propósito de reduzir os números de vítimas fatais, a campanha buscou incentivar as denúncias pelas mulheres vítimas de violência e, também, de conhecidos ou parentes que souberem deste tipo de agressão a buscarem uma delegacia e realizarem boletins de ocorrência.

A campanha foi divulgada por meio de peças veiculadas em $\mathrm{TV}^{7}$, rádio, digital, mídia impressa e $\mathrm{OOH}$ (out-of-home). As peças publicitárias trouxeram histórias reais de mulheres que sofreram violências domésticas pelos ex-companheiros e demonstrava a disposição dos novos recursos para o atendimento das mulheres vítimas de agressão.

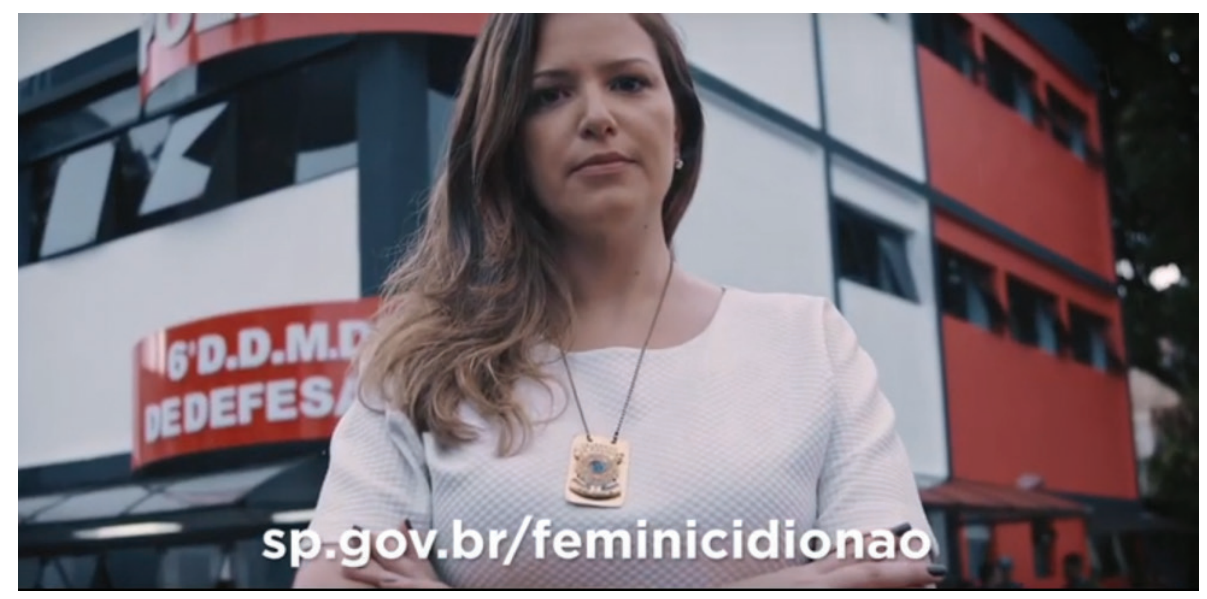

Figura 3: Campanha "Feminicídio não"10

Os materiais publicitários informam que foram disponibilizadas 10 novas Delegacias de Defesa da Mulher (DDMs) com atendimento 24h, inclusive finais de semana e feriado e, também, o aplicativo "SOS Mulher" que chama a polícia com um único toque.

Propaganda disponível em https://www.youtube.com/watch?time_continue=13\&v=So8iqN_aWbw - Acesso em 11 ago. 2019 
Das 10 novas delegacias 24h, sete foram disponibilizadas na capital e três no interior - Campinas, Santos e Sorocaba - e já foi percebido um aumento de $330 \%{ }^{8}$ no número de atendimentos nas delegacias $24 \mathrm{~h}$ devido as agressões ocorrerem, principalmente, em casa e fora do horário comercial.

O estado de São Paulo dispõe hoje de 133 unidades de Delegacias de Defesa da Mulher, sendo 16 na grande São Paulo, 9 na capital e 108 distribuídas no interior. Desse total somente as novas 10 delegacias funcionam $24 \mathrm{~h}$, as demais continuam funcionando de segunda a sexta-feira das $9 \mathrm{~h}$ às $19 \mathrm{~h}$ e nem todas são de atendimento exclusivo para a mulher.

O estado recebeu um projeto de lei para tornar todas as DDMs $24 \mathrm{~h}$, a qual foi uma promessa de campanha do atual governador João Dória e que chegou a ser aprovada pelos deputados da Assembleia Legislativa em 2018, mas foi vetada pelo governador com alegação de ser inviável o aumento de servidores em todas as DDMs do estado.

Nesta campanha foi informada, também, sobre a disponibilização do aplicativo "SOS Mulher", o qual possui um botão de alerta automático que, ao ser ativado, aciona a viatura policial mais próxima do local para atendimento, mas o serviço é exclusivo para quem possui medida protetiva.

\section{CONSIDERACÕES FINAIS}

Diante do levantamento realizado pela MP-SP, vemos que é necessária a providência de maior proteção à mulher e, também, as vítimas diretas e indiretas desta modalidade de crime que cresce absurdamente em nosso estado e em todo mundo.

Infelizmente, vemos também que a grande maioria de vítimas de feminicídio, consumado ou tentado, nunca registrou Boletim de Ocorrência ou obteve uma medida protetiva, decisão a qual facilita a aproximação do agressor que chega, 1/3 das vezes, ao feminicídio.

A partir desta constatação houve reação do governo do estado de São Paulo, mas

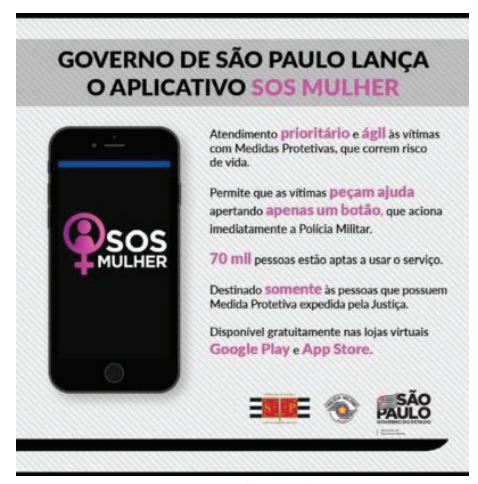

Figura 4: Aplicativo "SOS Mulher" - internet

Disponível em https://gruposulnews.com.br/cresce-numero-de-atendimentos-em-delegacias-de-defesa-da-mulher-na-zona-sul/ - Acesso em 12 ago. 2019 
em comparação ao número de municípios (645), vemos que ainda é pouco 10 novas DDMs com atendimento $24 \mathrm{~h}$ e as demais bases atendendo somente em horários comerciais e nem sempre com funcionárias mulheres (delegadas, escrivãs, policiais) ou locais exclusivos para o acolhimento da vítima que pode se sentir intimidada ou, até mesmo, ser humilhada.

Entendemos que a iniciativa de disponibilizar novas delegacias $24 \mathrm{~h}$ e o aplicativo "SOS Mulher" são uma vitória para a defesa da mulher e muito bem vindas, mas as mulheres precisam de mais proteção e mais incentivo para realizar as denúncias, mas carecem em se sentir seguras para tal decisão, pois podem correr mais riscos para fazer a denúncia de agressão e indicar o agressor para a justiça.

O possível agressor precisa entender que o feminicídio é um crime grave e, por isso, temos a disposição leis que agravam a pena para eles. A primeira providência para prevenção deste tipo de crime é que a mulher precisa ser bem orientada para saber buscar seus direitos por meio do boletim de ocorrência e medida protetiva, mas para que se consiga tal atitude por uma vítima é preciso, primeiramente, que ela saiba que terá um local seguro para onde possa buscar ajuda, se sentir acolhida / defendida e que haverá algum tipo de refúgio para ela e para os filhos e que, também, o homem saiba que a lei será cumprida em caso de agressão psicológica, física, sexual e/ ou patrimonial.

Mesmo as mulheres estando cada vez mais conscientes destes tipos de agressões, principalmente vindas do marido / companheiro ou namorado, precisam reagir com o não aceite deste tipo de tratamento tido, muitas vezes, como normais, mesmo sendo cenas de ciúmes, o que colabora na desconstrução da ideologia de inferioridade feminina, mas ainda existe muita resistência em denunciar ou se afastar do agressor por, muitas vezes, ele ser o único meio de sustento da família.

A partir disso, podemos perceber que a violência, muitas vezes, é aceita e se inicia dentro de casa / família, em que a criança sofre ou assiste a agressões contra a sua mãe e entende que aquele é o modo de tratar a mulher, ou ser tratada. Aprende que deve ser submissa e aceitar o que o marido fizer, pois depende dele financeiramente, ou emocionalmente, aprendizado este que resulta na insegurança tanto das meninas em conseguir se livrar de um relacionamento abusivo, quanto dos meninos que aprendem que precisam demonstrar sua masculinidade para dominar a mulher.

Apesar desta situação da mulher na sociedade, é incontestável todo o progresso que a mulher conquistou como o direito ao voto, trabalhar fora, 
escolherem seus maridos, licença maternidade, entre outros êxitos, mas a luta pela igualdade ainda repercute bravamente pelo mundo em busca de reconhecimento, respeito e liberdade.

Com isso, entendemos que é preciso conscientizar, a partir da educação primária, que qualquer tipo de violência não é o correto a fazer e é preciso denunciar / pedir ajuda em qualquer tipo de abuso. Percebemos que a busca deste novo tipo de educação pode ajudar a aprofundar futuramente esta mudança necessária na cultura patriarcal enraizada no imaginário social que, ainda, visualiza a mulher como submissa / dependente.

Para os tempos atuais é preciso empenho da humanidade em respeitar a mulher em todas as diretrizes sociais e culturais contribuindo, assim, no fortalecimento e união de todos os seres, independente de seu gênero, cor, nacionalidade ou religião, contribuindo para um futuro de liberdade com respeito ao próximo.

\section{REFERÊNCIAS}

BIGLIARDI, A. M.; ANTUNES, M. C. Violência contra mulheres - A vulnerabilidade feminina e o perfil dos agressores. São Paulo: Juruá, 2018.

BOURDIEU, P. A dominação masculina. Rio de Janeiro: Bertrand Brasil, 2007.

BRITO, G. F. D.; PAULA, J. V. D. A masculinidade e a ideologia: socialização masculina. Opsis, Catalão, p. 173-188, jul. 2013.

FINCO, D. Socialização de gênero na educação infantil. Fazendo Gênero - 8, Florianópolis, 25 ago. 2019. Disponivel em: <http://www.fazendogenero.ufsc.br/8/sts/ST10/Daniela_Finco_10.pdf>.

MONICK, E. Falo - a sagrada imagem do masculino. São Paulo: Paulinas, 1993.

REPÚBLICA, P. D. Planalto. Planalto, 2004. Disponivel em: < http://www.planalto.gov.br/ccivil_03/_ Ato2004-2006/2004/Lei/L10.886.htm>. Acesso em: 23 jul. 2019.

RUSSE, D.; CAPUTTI, J. The politics of women killing. New York: Twayane Publisher, 1992. 